\title{
Modeling Study of Soot Formation and Oxidation in DI Diesel Engine Using an Improved Soot Model
}

\author{
Xiaobei Cheng', Liang Chen ${ }^{1}$, Guang Hong ${ }^{2}$ Fangqin Yan $^{1}$, Shijun Dong ${ }^{1}$ \\ 1. School of Energy and Power Engineering, Huazhong University of Sci. \& Tech., Wuhan, Hubei, China \\ 2. Faculty of Engineering \& IT, University of Technology, Sydney, Australia
}

\begin{abstract}
Particulate emission is one of the most deleterious pollutants generated by Diesel fuel combustion. The ability to predict soot formation is one of the key elements needed to optimize the engine performance and minimize soot emissions. This paper reports work on developing, a phenomenological soot model to better model the physical and chemical processes of soot formation in Diesel fuel combustion. This hybrid model features that the effect of turbulence on the chemical reaction rate was considered in soot oxidation. Soot formation and oxidation processes were modeled with the application of a hybrid method involving particle turbulent transport controlled rate and soot oxidation rate. Compared with the original soot model, the in-cylinder pressures, heat release rate and soot emissions predicted by this hybrid model agreed better with the experimental results. The verified hybrid model was used to investigate the effect of injection timing on engine performance. The results show that the new soot model predicted reasonable soot spatial profiles within the combustion chamber. The high temperature gase zone in cylinder for hybrid model case are distributed broadly soot and NOx emission dependence on the start-of-injection (SOI) timing. Retarded SOI timing increased the portion of diffusion combustion and the soot concentration increased significantly with retarding of the fuel injection timing. The predicted distributions of soot concentration and particle mass provide some new insights on the soot formation and oxidation processes in direct injection (DI) engines. The hybrid phenomenological soot model shows greater potential for enhancing understanding of combustion and soot formation processes in DI diesel engines.
\end{abstract}

Keywords: Improved soot model; diesel engine; combustion; soot formation;

\section{Introduction}

Particulate emission is one of the most deleterious pollutants generated during diesel combustion. Newly promulgated Environmental Protection Agency (EPA) standards impose very strict regulations on particulate emission levels with increased emphasis on the particle size. To meet the new regulations, it is required to improve the understanding of the mechanisms of soot particle formation and oxidation in 
internal combustion engines.

The detailed kinetic mechanisms of soot formation in the pyrolysis, the combustion of hydrocarbons and the soot particle dynamics have been studied extensively [1-3]. Since the early 1970s when Khan et al [4] first presented a model for the prediction of soot production from diesel engine, a variety of soot models with different levels of complexity have been proposed and applied to multi-dimensional simulations. In 1985, Hiroyasu [5] reviewed the soot model development between 1962 and 1984, and proposed a two-step empirical soot model involving only two reaction steps: (1) the formation step in which soot is linked directly to fuel vapor molecules, (2) the oxidation step modeling the destruction of soot particles via the attack of molecular oxygen.

Patterson et al [6] pointed out that Hiroyasu' soot model or its revisions [7] under -predicted the peak in-cylinder soot concentration. Instead of using the original Hiroyasu' soot model, Patterson et al adopted the value of the activation energy proposed by Belardini et al [7] for the soot formation step, and replaced the soot oxidation formulation by the Nagle and Strickland-Constable oxidation model [8]. Due to its simplicity, this modified version of the two-step soot model [6] has been widely used.

In 1994, Fusco et al [9] proposed an eight-step phenomenological soot model and questioned the applicability of the two-step empirical models applied to a wide range of operation conditions in diesel engines. They suggested to relax the strong tie between fuel vapor molecules and soot by introducing two intermediate species. The eight global reaction steps include particle inception, particle coagulation, surface growth, and surface oxidation, as well as global reaction steps for intermediate species formation and oxidation. However, as coupling of large-scale chemical kinetic mechanisms was not pursued at that time, they assumed soot precursor radical and the soot growth species to be the products of pure fuel pyrolysis. Each of the species was represented only by one global reaction step. Aiming at a better description of the particle physics of soot formation, Kazakov and Foster [10] suggested using a generic species for the soot surface growth and a rate constant of coagulation valid from the molecular to the continuum regimes. In this 
manner, the description of the soot formation process became more physically sound compared to the two-step empirical model and, yet, this model retained its simplicity.

In 2001, a chemical mechanism that coupled a phenomenological soot model with complex chemistry for gas-phase soot precursor formation and oxidation was described by Tao et al [11]. The mechanism consisted of 65 species and 268 reactions, and was incorporated into KIVA CFD calculations for the study of the detailed flame structure of diesel sprays [12]. In 2009, a nine-step phenomenological soot model wasdeveloped using KIVA-3V code for predicting soot formation and oxidation processes in diesel engines by Tao et al [13]. The model involved nine generic steps, i.e., fuel pyrolysis, precursor species (including acetylene) formation and oxidation, soot particle inception, particle coagulation, surface growth and oxidation. The numerical models have been continously developed since then with improved complexity and capability [14-16].

Multi-dimensional computer simulations have become essential in the modern engine design. The ability to predict soot formation is one of the key requirementss to design an engine with minimum soot and other pollutant emissions and high efficiency. Although the application of multi-dimensional modeling to diesel engines appears promising in the engine design field, prediction of soot formation and oxidation in combustion is still challenging. A variety of soot models ranging from simple empirical correlations relating the amount of particulates in the exhaust to very detailed descriptions of pre-particle chemistry and soot particle dynamics have been proposed for engine simulations [16-19].

Comprehensive models, on the other hand, treat the process of soot formation in considerable details and are becoming nearly quantitative for simple combustion systems. These models require the explicit knowledge of the comprehensive reaction mechanisms in fuel pyrolysis and oxidation. Such mechanisms are normally very complex and not available for multi-component blends of diesel fuels in practice. So far research in this aspect has been focused on relatively simple hydrocarbon fuels such as n-heptane. Furthermore, the uncertainty in modeling the sub-mechanisms in formation of polycyclic aromatic 
hydrocarbons $(\mathrm{PAH})$, widely regarded as soot particle precursors and needed for the description of pre-particle chemistry is still an issue to be addressed. Another issue equally important is the interaction between the detailed chemistry and the turbulent mixing on a sub-grid level.

To address the above issues, a phenomenological model combining soot particle turbulent transport controlled rate and soot oxidation rate has been developed for simulating the combustion in a direct injection diesel engine. This model was validated against the experimental data derived from a single-cylinder DI Diesel engine. The process of soot formation and oxidation was analyzed to understand the effects of engine operating variables on soot emissions. The effect of different fuel injection parameters such as SOI on the characteristics of emissions from engine was also examined.

\section{Soot Model}

Phenomenological or semi-empirical models describe the complex process of soot formation and oxidation in terms of several global steps. Such an approach is particularly advantageous for the practical combustion simulations. On one hand, a simple system with a well-defined kinetic behavior is substantially easier to interpret and to calibrate for the operation conditions of interest. Soot formation is intrinsic to the diesel diffusion combustion. Considerable progress has been made in the last a few decades toward the advanced understanding of the physical mechanisms of soot formation and oxidation in combustion systems. However, the detailed mechanism of the soot formation and oxidation process in diesel engines is not so clear, although several theories have been proposed to explain these processes.

\subsection{Hiroyasu-Nagle and Strickland (HNS) Soot Model}

HNS is one of the most popular semi-empirical models for soot formation in diesel engines, as suggested by Hiroyasu and Kadota [20]. It includes only two steps: (1) the formation step, in which soot is linked directly to fuel vapor molecules, and (2) the oxidation step, which describes the destruction of soot particles via the attack of molecular oxygen. The net rate of change in soot mass $\dot{\mathrm{M}}_{\mathrm{s}}$ is the difference 
between the rate of soot formation $\dot{\mathrm{M}}_{\mathrm{sf}}$ and the rate of soot oxidation $\dot{\mathrm{M}}_{\text {so }}$, according to:

$$
\dot{M}_{\mathrm{s}}=\dot{M}_{\mathrm{sf}}-\dot{M}_{\mathrm{so}}
$$

the rates of soot mass formation and oxidation can be obtained from:

$$
\begin{gathered}
\dot{M}_{\mathrm{sf}}=K_{\mathrm{f}} M_{\mathrm{fv}} \\
\dot{M}_{\mathrm{so}}=K_{\mathrm{o}} M_{\mathrm{s}}
\end{gathered}
$$

where $K_{\mathrm{f}}$ is the formation rate coefficient; $K_{\mathrm{o}}$ is the oxidation rate coefficient; $M_{\mathrm{fv}}$ is the fuel vapor mass; $M_{\mathrm{s}}$ is the formed soot mass. The soot formation and oxidation rate coefficients, $K_{\mathrm{f}}$ and $K_{\mathrm{o}}$ can be expressed in Arrhenius form as follows:

$$
\begin{gathered}
K_{\mathrm{f}}=A_{\mathrm{f}} P^{0.5} \exp \left(-E_{\mathrm{f}} / R T\right) \\
K_{\mathrm{o}}=X_{\mathrm{O}_{2}} A_{\mathrm{o}} P^{1.8} \exp \left(-E_{\mathrm{o}} / R T\right)
\end{gathered}
$$

where, $A_{\mathrm{f}}$ and $A_{\mathrm{o}}$ are the pre-exponential factors; $E_{\mathrm{f}}$ and $E_{\mathrm{o}}$ are the activation energies; $X_{\mathrm{O} 2}$ is oxygen molar fraction; $R$ is the specific gas constant; $T$ is the gas temperature. The activation energies and Arrhenius pre-exponential constants were modified from Belardini et.al.[7] to fit the data of engine base case.

This model, however, was found to give relatively low peak in-cylinder soot concentrations. A more realistic prediction was obtained by using the Nagle and Strickland-Constable (NSC) oxidation model in replacement of Eq. (5) [21]. In this model, the carbon oxidation occurs by two mechanisms whose rates depend on the surface chemistry involving more reactive A sites and less reactive B sites, and the conversion of A sites to B sites. The chemical reactions are:

$$
\begin{gathered}
\mathrm{A}+\mathrm{O} 2 \rightarrow \mathrm{A}+2 \mathrm{CO} \\
\mathrm{B}+\mathrm{O} 2 \rightarrow \mathrm{A}+2 \mathrm{CO}
\end{gathered}
$$




$$
\mathrm{A} \rightarrow \mathrm{B}
$$

Base on Eqs. (3) and (5), the rate of soot oxidation $\dot{\mathrm{M}}_{\text {so }}$ is then replaced by the NSC oxidation rate:

$$
\dot{M}_{\mathrm{so}}=\frac{6 m_{\mathrm{c}}}{\rho_{\mathrm{s}} d_{\mathrm{s}}} M_{\mathrm{s}} \dot{M}_{\mathrm{t}}
$$

where $\dot{\mathrm{M}}_{\mathrm{t}}$ is net reaction rate; mc is the carbon molecular weight; $\rho_{\mathrm{s}}$ is the soot density; $d_{\mathrm{s}}$ is generally an averaged soot particle diameter.

2.2 A Hybrid Soot Particle Turbulent Transport Controlled Rate and Oxidation Rate Model

HNS soot model has also shown that two-step models have limited range of applicability. They do not provide the information regarding the mass concentration distribution of soot particles which, as mentioned above, is one of the issues of practical interest. Therefore, higher-level, semi-empirical models of soot formation are currently considered.

In the present modeling, the soot was formed and contained in the turbulent eddies within the flame, and the burn-up of soot was related to the dissipation of the turbulence. In the DI diesel engine with strong air swirl, the mixing rate depends on the fuel injection and air swirl processes. The soot formation rate and the soot properties vary with its nuclei particle size. The nuclei particle size is quite small ranging from 10 to $100 \mathrm{~nm}$ in diameter. Hence, the soot can be considered acting like the gas-phase species. The transport equation is based on a non-slip assumption. Non- or small- slip is assumed between the soot and the fluid. This assumption is an extension of the concept of a multi-component single-phase fluid changing to a multiphase fluid mixture. After the soot particles are produced from a combustion process, the soot particles are then convected by the medium of gas flow. Thus, the spatial distribution of soot is a function of the gas flow.

The basic transport equation of the soot model [22] was adopted in the present study with modifications that will be discussed later in the paper. The soot concentration transport equation is solved together with all other flow and spray equations as follows: 


$$
\frac{\partial M_{\mathrm{s}}}{\partial t}+\frac{\partial}{\partial x_{i}}\left(v_{i} M_{\mathrm{s}}\right)=\frac{1}{\rho_{\mathrm{s}}} \frac{\partial}{\partial x_{i}}\left(D_{\mathrm{s}} \frac{\partial M_{\mathrm{s}}}{\partial x_{i}}\right)+\dot{M}_{\mathrm{s}}
$$

where $v_{\mathrm{i}}$ is the velocity in the direction of space coordinates $i=1,2,3 ; \rho_{\mathrm{s}}$ is the soot density; $D_{\mathrm{s}}$ is the effective soot diffusivity which can be determined from [23]:

$$
D_{\mathrm{s}}=\frac{k_{\mathrm{B}} \cdot T \cdot C_{\mathrm{c}}}{3 \pi \cdot \mu \cdot d_{\mathrm{s}}}
$$

where $k_{\mathrm{B}}$ is Boltzman constant; $\mu$ is the gas viscosity. When the soot particle diameter approaches the same order as the mean free path $\lambda$ of the suspending fluid, the resisting force offered by the fluid is smaller than that predicted by the Stokes law. To account for non-continuum effects that the $d_{\mathrm{s}}$ becomes smaller and smaller, a slip correction factor $C_{\mathrm{c}}$ is introduced into Eq. (11) [23]. If $\mathrm{d}_{\mathrm{s}}>>\lambda$, then $C_{\mathrm{c}} \approx 1$ in the free molecule regime $D_{\mathrm{s}}$ varies as $d_{\mathrm{s}}-1$. On the other hand, if $d \mathrm{~s}<<\lambda$, then $C_{\mathrm{c}} \approx 1+\left(2 \lambda / d_{\mathrm{s}}\right)[1.257+$ $\left.0.4 \exp \left(-0.55 d_{\mathrm{s}} / \lambda\right)\right]$ and in the free molecule regime $D_{\mathrm{s}}$ varies as $\mathrm{d}_{\mathrm{s}}-2$.

The soot oxidation rate is proportional to the local concentration of soot and oxidant. In the realistic DI diesel engine combustion process, the oxidation reaction takes place on the surfaces of soot particles as soon as the soot particles formation occurs. In turbulent combustion, the soot particles contain within the turbulent eddies. The chemical reactions are interacted with the dissipation rate of unburned gas turbulent eddies due to the intermixing of soot nuclei particles and small scale turbulent eddies. These soot particles are burnt up swiftly with the dissipation of these eddies in soot oxidation zone. The soot formation and oxidation rates are determined by both of the chemical reactions rate and the dissipation rate of turbulent eddies [24]. Since the time scales in the chemical reactions are smaller than that of the turbulent transport processes, a hybrid soot oxidation rate model was developed with the effect of turbulent on the chemical reactions rate considered. The modes can be described by Eqs 12-15.

$$
\dot{\mathrm{M}}_{s o}=\min \left(S_{k}, S_{t 1}, S_{t 2}\right)
$$




$$
\begin{gathered}
S_{k}=C_{d} m_{s}\left(P_{O_{2}} / T_{g}^{0.5}\right) \exp \left(-E / R T_{g}\right) \\
S_{t 1}=C m_{s} \varepsilon / \kappa \\
S_{t 2}=C \frac{m_{o x}}{R_{f}}\left(\frac{m_{s} R_{s}}{m_{s} R_{s}+m_{f} S_{f}}\right) \frac{\varepsilon}{\kappa}
\end{gathered}
$$

where $C_{\mathrm{d}}$ is reaction rate coefficient and taken as $3.6 \times 1010 ; P_{\mathrm{O} 2}$ is pressure of oxygen; $m s m_{s}$ is the mass fraction of soot, $m_{\mathrm{f}}$ is the mass fraction of fuel; mox is the mass fraction of oxidant; $C$ is constant and taken as 4 [24]; $T_{\mathrm{g}}$ gas temperature $(K) . \kappa$ is the turbulent kinetic energy; $\varepsilon$ is the rate of its dissipation; $\varepsilon / \kappa$ is the eddy turnover time that represents the turbulent time scale; $R_{\mathrm{s}}$ is the chemical equivalence ratio of soot-oxygen; $S_{\mathrm{f}}$ is the chemical equivalence ratio of fuel-oxygen; $S_{\mathrm{k}}$ is the chemical kinetic oxidation rate, $S_{t 1}$ represents the mixing rate, and $S_{t 2}$ represents the oxidation rate.

The soot oxidation rate is proportional to the local soot concentration and mass fraction of oxidants. When local soot concentration or mass fraction of oxidants is zero, the soot oxidation rate is zero. On the other side, soot particles are surrounded by turbulent eddy in the turbulent combustion, which are oxidized quickly with the breakup of turbulent eddy at the soot oxidation region. Therefore, the oxidation rate of soot particles is affected by the breakup rate of the turbulent eddy.

In Eq. (12), min indicates the minimum of the three values. The physical interpretation of $\min$ is that the oxidation-combustion reaction occurs only in the micro-eddy current structure of turbulent eddy (Kolmogorov time scale of turbulent eddy). When the chemical time scale of the controlling component (the minimum in parenthesis) is greater than the Kolmogorov time scale, the quenching of the oxidation combustion reaction will occur. The equation could apply to the complex turbulent combustion of the diffuse combustion-based of diesel engines, and some coefficients should be adjusted. The equation contains the mean concentration of species without the fluctuating concentration, and from the Eq. (12) the spatial distribution of soot particles is mainly affected by the turbulence scale, chemical equivalent ratio and the mixture fraction.

In the present study, the hybrid soot phenomenological soot model as described by Eqs. (1), (2) and (12) was developed using KIVA-3V2 code as a solver, nsmed as "present soot model". The HNS soot 
model $[22,25]$ is named as "original model” for comparison.

\section{Computational Models}

The multi-dimensional computations were performed using KIVA-3V2 code enhanced with the improved sub-models. With the addition and modification of many built in sub-models, it is now being widely applied and validated for engine combustion simulations. In the KIVA simulation, the turbulent flows were modeled using a modified RNG $k-\varepsilon$ turbulence model developed by Han and Reitz [26], which accounts for the variable gas density in engine flows. The liquid injection and atomization was simulated using the 'blob' injection model proposed by Reitz and Diwakar [27]. The fuel drop parcels are injected with a characteristic size equal to the nozzle hole diameter, and the number of drop parcels injected is determined from the fuel flow rate. The spray dynamics was modeled using the wave breakup model developed by Reitz [28]. The atomization and breakup are simulated with a Kelvin-Helmholtz jet stability model.

Diesel combustion process can be divided in two periods: ignition and combustion. The ignition process was modeled using the Shell model developed by Halstead et al. [29]. This model has been well developed for simulating the auto-ignition in diesel engines. Once the fuel reaches a specified temperature in a cell, the combustion model is switched on. When the temperature in a cell reaches $1000 \mathrm{~K}$, the combustion takes place with the formation of soot and NOx.

The combustion model is based on the laminar and turbulent characteristic time model [22], which was used to calculate the rate of change of molar concentration during combustion.

$$
\frac{d Y_{i}}{d t}=-\frac{Y_{i}-Y_{i}^{*}}{\tau_{\mathrm{c}}}
$$

where $Y_{\mathrm{i}}$ is molar concentration of species $i, Y_{i}^{*}$ is a is thermodynamic equilibrium value of species $i . \tau_{\mathrm{c}}$ is the characteristic time to achieve thermodynamic equilibrium. The characteristic time is calculated from the laminar and turbulent time scales, can be formulated as: 


$$
\tau_{\mathrm{c}}=\tau_{\mathrm{l}}+f \cdot \tau_{\mathrm{t}}
$$

The delay coefficient, $f$, determines the influence of turbulence on combustion, The laminar time scale $\tau_{1}$ is obtained from the oxidation of n-dodecane, which is derived from the correlated one-step reaction rate from a single droplet auto-ignition experiment. The turbulent timescale $\tau_{\mathrm{t}}$ is proportional to the time of eddy turnover

$$
\tau_{\mathrm{t}}=C \cdot \kappa / \varepsilon
$$

where $C_{1}=0.1$ used in $R N G k-\varepsilon$ turbulence model.

In the present study, the extended Zeldovich thermal mechanism as presented by Heywood [30] was applied to calculate nitric oxide (NO) emission formation in the diesel engine.

\section{Experimental and Simulation Conditions}

The tested engine specifications and calculation conditions are listed in Tables 1 . The single engine is equipped with an A-type injection pump, which delivers fuel with maximum pressure up to $45 \mathrm{MPa}$. Four-hole injectors ensure very good fuel atomization, which is injected into the shallow $\omega$-shaped combustion chamber placed asymmetrically in the piston crown. High-intensity air swirl induced by a spiral shaped intake valve channel enables fast evaporation of highly atomized fuel and fast mixing of fuel vapors with air, thus preventing impingement of fuel into the walls of the combustion chamber. A low sulfur diesel fuel was used in this experiment, which was produced by China Petrochemical Corporation. The fuel properties provided by the company are shown in Table 2 .

The computation was carried out at varied start of injection (SOI) timing of $25^{\circ}, 20^{\circ}$, and $12^{\circ} \mathrm{CA}$ BTDC and 75\% rated load. Fig. 1 shows the computational mesh of the combustion chamber at the top-dead-centre (TDC). Because the four orifices of fuel injector are equally dispersed, one-fourth of the cylinder domain $\left(90^{\circ}\right.$ sector) was then simulated. The adaptive grid employed has about 27,690 cells at the TDC and 8,550 cells at the bottom-dead-centre (BDC). 
In-cylinder pressure was measured using a Kistler 6125B piezoelectric pressure transducer, coupled with a charge amplifier $(5011 \mathrm{~B}$, Kistler). The net heat release rate (NHRR) analysis and combustion gas temperature were calculated with the measured in-cylinder pressure data in a single-zone combustion model based on the first law of thermodynamics [30]. The data acquisition card, National Instrument Inc, model 6013, was used to allow data acquisition at $250 \mathrm{KBS} / \mathrm{s}$. The emission data of $\mathrm{NOx}, \mathrm{CO} / \mathrm{CO}_{2}$ and $\mathrm{THC}$ were recorded during the experiments. was measured using the California Analytical Instruments (CAI), model 400 HCLD for $\mathrm{NO} / \mathrm{NO}_{\mathrm{X}}$, model 300 NDIR for $\mathrm{CO} / \mathrm{CO}_{2}$, model $300 \mathrm{HFID}$ analyzers for HC. Particle mass concentrations were measured by tapered element oscillating microbalance (TEOM) Model 1105. Heat release analysis was performed to determine combustion characteristics, estimated temperatures, and residual gas fractions.

To ensure the reliability and repeatability of the measured data, each of the engine test condition as listed in Table 3 was first set by running the engine for at least 15 min until the steady state was reached. The baseline was at engine speed of $1500 \mathrm{r} / \mathrm{min}$, SOI timing of $25^{\circ} \mathrm{BTDC}$ and $75 \%$ rated load with medium torque of $45 \mathrm{~N} \cdot \mathrm{m}$.

A dilution tunnel was applied to sample particles emissions. Dried and cleaned compressed air was heated to the temperature equal ti that of the engine exhaust gas before flowing into the dilution tunnel. All transmission pipes were insulated and the interior wall temperature of the pipes was maintained at 220 to $260^{\circ} \mathrm{C}$. The measurement point was ? mm downstream of the engine exhaust port. The length of the connecting pipes was minimized to reduce the thermal conductivity deposition and surface condensation of particulate matters in the transmission pipes. Three samples were taken at each test condition with sample size of five.

\section{Results and Discussions}

4.1 In-Cylinder Combustion Analysis 
An important prerequisite to obtaining accurate predictions of the in-cylinder soot formation/oxidation processes is to capture certain information on combustion experimenatlly. To achieve this, the simulated combustion characteristics in terms of ignition delay (ID) periods and peak pressures are validated through direct comparisons against experimental results. As the first step in simulation, the sub-models gverning the ignition, combustion, and spray atomization were calibrated in order to verify the numerical models by experiments. The Firgure 2 shows the comparison between the numerical and experimental results of model in-cylinder pressure and the heat release rate data for the engine baseline case for model verification.

The comparison in Figure 2 is made between the present hybrid model and original model with both against the experiments. As shown in Fugure 2, the numerical results agree well with the experimental one, exceot the overpredicted peak pressure. The difference between the numerical and experimental data falls within $4.0 \%$. The maximum difference in cylinder pressure data is $3.6 \%$ when the results produced by the present hybrid model are compared with that from experiments. It is $4.5 \%$ for the original model. As also shown in Figure 2, the original model overpredicts the the HRR peak value while the present hybrid model under predicts. In overall, compared with the original model, the present hybrid model shows a better agreement with the experiments than the original model does. This indicates that the present hybrid model is of higher accuracy than the original model is in the baseline experimental conditions. The numerical and experimental results of heat release rates agree very well during the premix and diffusion combustion processes. The peak heat release rate is overestimated at $-3^{\circ} \mathrm{CA}$ ATDC which is right after the auto-ignition. This is due to the error in the ignition delay model which underestimated the temperature of the cool flame during ignition delay. The computed ignition time occurs at about $-8^{\circ}$ CA ATDC and the one from the experiment at ?CA ATDC. The premixed combustion is dominant at the early stage of the combustion process, which forms the first peak of its heat release rate.

Soot production processes depend on the fuel composition, cylinder gas pressure, temperature, and local fuel and oxygen concentration. The soot predicted by the two soot models were compared with one 
experimental data in Fig. 3. The soot mass concentration predicted by the present soot model agrees very well with the experimental one. However, the soot mass concentrations predicted by the two models are significantly different. Firstly, the soot mass concentration predicted by the original model is much greater than that predicted by the present hybrid model, especially after the soot mass reaches its peak value. Secondly, the present hybrid model predicted slightly earlier timing of the peak in-cylinder soot quantity than the original model does. Comparing with the measured soot data, the present hybrid soot model demonstrated a better agreement.

Fig. 4 shows the cross-section "S-S" which is obtained by rotating $45^{\circ}$ on the $\mathrm{X}-\mathrm{Y}$ plane and passing through the spray axis for the visualization results of iso-surfaces. It shows that the impingement point of fuel spray tip locates near to the upper edge of the piston bowl. The time of the plot is at $5^{\circ} \mathrm{CA}$ ATDC, when the premixed combustion phase has just completed. At this time, the total soot yield is almost the highest and the flame tip has impinged on the piston wall (see temperature distribution in Fig.7). Fig. 4 also shows that the injected fuel reaches the edge of the piston bowl. The vaporization of liquid-fuel starts in the midway between the nozzle and the spray tip. The fuel vapor continues to penetrate beyond the spray tip, and spreads ending midway in the flame plume. Part of the unburned fuel vapor is around at the rim of the bowl, but most of the fuel vapor diffuses in the top region of engine piston due to the effect of the strong swirl gas motion in the engine cylinder. The combustion takes place simultaneously on the top of piston and inside the piston bowl. The nucleation of soot starts to form in the region where the ignition occurs. Soot transport is significantly influenced by the charge motion during the expansion stroke. A typical velocity vector plot can be found in Fig. 5. The vortex pushes the fuel into the surface of the engine piston, and then, the concentration of fuel vapor increases when approaching the chamber wall. As a result, the fuel burnss near the surface of the engine piston. The fuel vapor is accumulated and forms extremely rich fuel areas at the near wall regions of the chamber. This phenomenon can be observed from the contribution of fuel vapor concentration fields shown in Fig. 4. 
Fig. 6 shows the detailed temperature distribution in cylinder when using different soot models. The spatial distribution of high temperature gas at $5^{\circ} \mathrm{CA}$ ATDC is broader and the peak temperature is lower in the results of the present hybrid model than that of the original model The increased turbulence diffusion level further loweres down the peak combustion temperatures to $2460 \mathrm{~K}$.

As slso shown in Fig. 6, in the modeling with the present hybrid model, high temperature combustion starts in the region close to the bowl lip and along the bottom of the bowl. The bulk of the high-temperature gas moves down to the piston bowl wall and is swept inward along the bottom of the bowl during expansion stroke. The remaining high-temperature gas moves towards the liner in the squish region. After that, the high-temperature gas in the bowl moves up with a tumble-like motion, and is mixed with the oxygen-rich charge in the central region of the bowl. This latter mixing process, occurring beyond about $10^{\circ} \mathrm{CA}$, is believed to be beneficial for reducing soot oxidation.

Fig. 7 shows the iso-surfaces of soot, $\mathrm{NO}_{\mathrm{x}}$ and oxygen mass fractions in the combustion chamber at $5^{\circ} \mathrm{CA}$ ATDC and $20^{\circ} \mathrm{CA}$ ATDC, predicted by the present hybrid model. The results show that the soot particles start to be formed at $-7^{\circ}$ ATDC, and appears in a large number in the spray tip near the wall of the piston bowl at $5^{\circ} \mathrm{CA}$ ATDC. The high soot mass concentration appears at the upstream of the fuel jet. The soot cloud which is distributed into the squish region moves towards the cylinder piston top and wall liner at $20^{\circ} \mathrm{CA}$ ATDC. This means that soot particles move to the squish area due to the outward squish flow. A high temperature region (diffusion flame) surrounding the soot-filled central region (near the wall) is noticable. The extent of the diffusion flame is confined to a certain distance from the nozzle tip. These phenomena are in agreement with the diesel flame structure in the conceptual model proposed by Dec [31]. At $20^{\circ} \mathrm{CA}$ ATDC, the outward squish flow draws unburned fuel out of the bowl and mixes it with air. Most of the soot is formed between the bowl and squish. The diffusion combustion takes place in the squish area and the soot formed in the high temperature region. After $20^{\circ} \mathrm{CA}$ ATDC, the piston downward motion governs the flow inside the cylinder whereas the outward squish flow is weakened. 
Since the soot emission is controlled by the dynamic characteristics of the fuel-air mixture flame, the soot formation processes depend on the temperature, local fuel and oxygen concentration inside the engine. The air-fuel ratio obviously affects the soot formation. The temporal evolution of the soot mass concentration firstly increases and then reaches the maximum of soot mass concentration when the global formation and oxidation rates are equal. Although the soot oxidation increases with the increase of the combustion temperature, the soot formation is also increased gradually with the increase of the number of fuel molecules. The comparison between Fig. 7(a) and Fig. 7(c) shows that the soot mass concentration field is always high in the region with rich fuel mixture,where $\mathrm{OH}$ mass fraction is lean. This means that the oxidation of soot is limited by the low local oxygen concentration.

The three-dimensional spatial distributions of the soot particles during the combustion and expansion stroke predicted by the present hybrid model and the original model are compared in Fig. 8. Like the temperature distributions, which show no significant high temperature regions along the bowl walls and bottom, the soot mass concentration shown in Fig. 8 is also more homogeneously distributed due to the lower temperature. As shown in Fig.3, peak soot mass concentrations predicted by the present hybrid model are significantly lower than that predicted by the original model. This phenomenon may be explained by the results shown in Fig. 7. As shown in Fig. 7(a), at $-5^{\circ} \mathrm{CA}$ ATDC, the soot particles start to be formed at the spray tip near the wall of piston bowl. The calculation results of the soot formation time and position are consistent in both soot models. As shown in Fig. 7 (b) and (c), the soot particles are moved to the squish area due to outward squish flow at $5^{\circ} \mathrm{CA}$ ATDC, and most of the soot is formed between the bowl and squish at $20^{\circ} \mathrm{CA}$ ATDC. The asymmetric distribution of soot particles in the bowl is due to the accentrics between the bowl and the engine. At $50^{\circ} \mathrm{CA}$ ATDC, the downward piston motion governs the flow inside the cylinder whereas the outward squish flow is weakened. However, a significant difference between the two model predictions is shown in Fig. 8. The present hybrid soot model takes into account the soot concentration transport with air flow in cylinder and the effect of turbulent on the chemical reactions rate 
was also considered. In addition to the dependence of temperature, the present hybrid soot model predicts a stronger dependence of the soot oxidation rate on the turbulent kinetic energy during the expansion stroke than the original empirical model in the same flow conditions. The soot particles were widely distributed in the lower part of a cylinder in Fig. 7 (d). The present hybrid model is more able to predict the soot particles spatial distribution characteristics in cylinder.

\subsection{Effect of Injection Timing on soot formation}

The computational results are highly sensitive to the different fuel injection timings using the same spray, ignition and combustion models. The start of injection (SOI) timing of 12 - $12 \mathrm{SOI}$ ) and $20^{\circ} \mathrm{CA}$ BTDC (-20 SOI) was chosen as the retarded cases to compare the results with the baseline case of SOI timing of $25^{\circ} \mathrm{CA}$ BTDC (-25 SOI). Fig.9 and Fig.10 show the cylinder pressure, heat release rate and in-cylinder temperature for $-25^{\circ},-20^{\circ}$ and $-12^{\circ}$ SOI timings, respectively. As shown in Fig.9, the peak cylinder pressure was decreased by $20 \mathrm{Bar}$ and the combustion duration was delayed by $15^{\circ} \mathrm{CA}$ when the injection timing was retarded from $-25^{\circ} \mathrm{SOI}$ to $-12^{\circ} \mathrm{SOI}$. Correspondingly, The time period of premixed combustion which shows peak heat release rate was reduced, whereas the time period of diffusion combustion which shows subsequent low heat release rate was increased with the retarded SOI timing, as shown in Fig.9. The combustion duration increase due to the low temperature in the retarded case. This indicates that the retarded SOI timing makes the combustion to take place with rich air-fuel mixture, resulting in more unburned fuel to be pyrolyzed into the acetylene and precursor.

The average temperature in $-12^{\circ} \mathrm{SOI}$ retarded case was lower than that in $-25^{\circ} \mathrm{SOI}$ case until $30^{\circ} \mathrm{CA}$ ATDC as shown in Fig.10. Once the combustion takes place, the in-cylinder temperature rises rapidly to its peak value and then starts to drop in the expansion stroke.

Fig. 11 shows the soot mass concentration varying with time at three SOI timings, as predicted by the present hybrid model. As shown in Fig. 11, the peak soot mass reduces with the retarded injection timing, and the later injection timing results in greater peak value of the soot mass. This is because that with earlier 
injection timing, more soot can be formed in higher temperature environment and longer duration for oxidization.

As shown in Fig.9 and Fig.10, in $-25^{\circ} \mathrm{CA}$ SOI case, the cylinder pressure and the average combustion temperature are higher than the other cases, resulting in the highest NO emission. Due to the constant engine speed, the $\mathrm{OH}$ concentration at different injection timings is consistent. With the decrease of the cylinder pressure and the combustion temperature, NOx emission was reduced. Therefore, NOx emissions is strongly related to the cylinder temperature and oxygen concentrations. Although it leads to a slight reduction of thermal efficiency and slight increase of exhaust gas temperature and fuel consumption rate, the retardation of fuel injection timing results in reduced NO emission significantly.

In general, the formation of booth soot and NOx strongly depend on the air/fuel ratio and combustion temperature. However, the soot and NOx concentration show show opposite effect of SOI timing in Figs 11 and 12. The soot mass, as shown in Fig.11, increases with the retarded SOI timing while the NOx, as shown in Fig. 12, decreases with the retarded SOI timing. The maximum soot formation rate does not appear in the regions where the combustion temperature is the highest. For $-25^{\circ}$ SOI case, the computed average peak combustion temperature reaches $1850 \mathrm{~K}$ at $10^{\circ} \mathrm{CA}$ ATDC (the computed transient peak combustion temperature reaches $2037 \mathrm{~K}$ at $20^{\circ} \mathrm{CA}$ ATDC, see in Fig.7 (a) ), while the predicted peak soot mass fraction appears at $2.5^{\circ} \mathrm{CA}$ ATDC. The predicted results also show that when the flame temperature is above $2300 \mathrm{~K}$, the soot concentration in combustion diffusion flame is negligible. The rate of soot oxidation achieves at the highest value when the flame temperature is between $2300 \mathrm{~K}$ to $2400 \mathrm{~K}$. High temperature and lean fuel are the most important factor to form the soot emissions. When the combustion rate is reduced with the retarded SOI timing, the combustion temperature decreases and the oxidation rate of soot is reduced.

\section{Summary and Conclusions}

A hybrid phenomenological soot model that includes particle formation and oxidation rates was 
developed by using the KIVA-3V2 code as a solver. The effect of turbulence on the chemical reaction rate was considered in the submodel for predicting the soot oxidation rate. Simulation results were compared with experiments to verify and with the original model to identify the improvement in the present hybrid model. The predicted in-cylinder pressures, heat release rate and soot emissions agreed well with the experimental ones. The verified hybrid model was used to evaluate the effect of direct injection timing on soot formation, NOx generation and combustion characteristics. The major conclusions are drawn as follows.

(1) The present hybrid soot model predicts a strong dependence of the soot oxidation rate on the turbulent kinetic energy during the expansion stroke than the original empirical model does. The soot particles start to be formed at the spray tip near the wall of piston bowl and then moved to the squish area due to outward squish flow at $5^{\circ}$ ATDC. Most of the soot is formed in the region between the bowl and squish at $20^{\circ}$ ATDC.

(2) The spatial distribution of high temperature gas at $5{ }^{\circ} \mathrm{CA}$ ATDC is broader and the peak temperature is lower predicted by the present hybrid model than that predicted by the original model. As predicted by the present hybrid model, the increased turbulence diffusion effectively reduced the peak combustion temperatures. The high temperature gase zone in cylinder for hybrid model case are distributed broadly and evenly throughout the bowl as well as in the squish region.

(3) The hybrid soot model takes into account the soot concentration transport with air flow in cylinder and the effect of turbulent on the chemical reactions rate was also considered. The present hybrid model has improved the prediction of the soot concentration distribution in cylinder, as its result shows that soot mass concentration is more homogeneously distributed than that predicted by the original model.

(4) The soot emission increases significantly with retarded fuel injection timing. Less soot formed in earlier injection timing cases may be due to the the higher temperature environment in the combustion chamber and longer time duration for soot oxidation. NOx concentration decreases with retarded SOI timing. 
Simulation results show that the processes of soot and NOx formation are predominantly governed by the local fuel-air ratio, in-cylinder temperature, and the engine operating conditions.

(5) The predicted distributions of soot concentration and particle mass provide some new insights on the soot formation and oxidation processes in DI engines. The hybrid phenomenological soot model has potential for enhancing understanding of combustion and soot formation processes in DI diesel engines, especially when in situ measurement is not available.

\section{Acknowledgments}

This work was supported by the State Nature Science Foundation of China (No.51176056).

\section{References}

[1] H. Wang, M. Frenklach, Combustion and Flame, 10 (1997) 173-221.

[2] F. Mauss, T. Schafer, H. Bockhorn, Combustion and Flame, 99 (1994) 697-705.

[3] H. Pitsch, H. Barths, N. Peters, SAE Technical Papers 962057, 1996.

[4] I. M. Khan, G. Greeves, C. H. T. Wang, SAE Technical Papers 730169, 1973.

[5] H. Hiroyasu, COMODIA 85, 1985, 53-75.

[6] M. Patterson, S. C. Kong, G. Hampson, R. D. Reitz, SAE Technical Papers 940523, 1994.

[7] P. Belardini, C. Bertoli, A. Ciajolo, A. D’Anna, N. Del Giacomo, SAE Technical Papers 922225, 1992.

[8] J. Nagle, R. F. Strickland-Constable, Proceedings of the Fifth Carbon Conference, Part 1, 1962, pp. 265-325.

[9] A. Fusco, A. L. Knox-Kelecy, D. E. Foster, COMODIA 94, 1994, 571-576.

[10] A. Kazakov, D. E. Foster, SAE Technical Papers 982463, 1998.

[11] F. Tao, V. I. Golovvitchev, J. Chomiak, COMODIA, 2001, 92-100.

[12] F. Tao, Ph.D Thesis, Chalmers University of Technology, 2003.

[13] F. Tao, R. D. Reitz, D. E. Foster, Y. Liu, International Journal of Thermal Sciences 48 (2009) 1223-1234.

[14] V. Gopalakrishnan, J. Abraham, Combustion Science and Technology 176 (2004) 603-641.

[15] N. Sung, S. Lee, H. Kim, B. Kim, Proc. of the Instn. Mech. Engrs. Part D: Journal of Automobile Engineering 217 (2003) 403-413. 
[16] F. Tao, D. E. Foster, R. D. Reitz, Proceedings of the Combustion Institute 31 (2007) 2991-2998.

[17] A. Garo, R. Said, R. Borghi, In: Bockhorn, H., editor. Soot Formation in Combustion-Mechanisms and Models; Springer-Verlag, Berlin, Heidelberg, 1995, pp. 527-550.

[18] F. Tao., Y Liu, B. A. RempelEwert, D. E. Foster, R. D. Reitz, D. Choi, P. C. Mile, SAE Technical Papers 2005-01-0121, 2005.

[19] P.A. Tesner, T.D. Snegirio, V.G.. Knorre, Combustion and Flame 17 (1971) 253-260.

[20] H. Hiroyasu, T. Kodota, SAE Technical Papers 760129, 1976.

[21] S.C. Kong, Z. Han, R.D. Reitz, SAE Technical Papers 950278, 1995.

[22] B.F. Magnussen, B.H. Hjertager, In Sixteenth Symposium on Combustion, The Combustion Institute, Pittsburg, USA, 719-729, pp. 1976.

[23] R.C. Flagan, J.H. Seinfeld, Prentice-Hall Inc., New Jersey, USA, 1988.

[24] I.M. Kennedy, Prog. Energy Combust. Sci. 23 (1997) 95-132.

[25] A.A. Amsden, Los Alamos National Laboratory Report LA-13313-MS, USA, 1997.

[26] Z. Han, R.D. Reitz, Journal of Combustion Science and Technology 106 (1995) 267-295.

[27] R.D. Reitz, R. Diwakar, SAE Technical Papers 870598, 1987.

[28] R.D. Reitz, Atomization and Spray Technology 3 (1987) 309-337.

[29] M. P. Halstead, L. J. Kirsch, A. Prothero, P. Quinn, Proc. Roy. Soc. Lond. A346 (1975) 515.

[30] J.B. Heywood, McGraw-Hill Book Company, USA, 1988.

[31] J. E. Dec, SAE Technical PaperS 70873, 1997. 


\section{Tables:}


Table 1 Engine specifications

\begin{tabular}{|c|c|}
\hline Type & $\begin{array}{c}\text { Single-cylinder, four-stroke } \\
\text { direct injection, diesel engine }\end{array}$ \\
\hline Bore (mm) & 100 \\
\hline Stroke (mm) & 115 \\
\hline Displacement $\left(\mathrm{cm}^{3}\right)$ & 903 \\
\hline Compression ratio & 17.4 \\
\hline Swirl ratio & 1.8 \\
\hline Power/ Speed(kW/rpm) & $9.5 / 1600$ \\
\hline Type of injector(holes/mm) & $4 \times 0.28$ \\
\hline Injection timing $\left({ }^{\circ} \mathrm{CA}\right.$ ATDC) & $-12 /-20 /-25$ \\
\hline Injection duration $\left({ }^{\circ} \mathrm{CA}\right)$ & $20^{\circ} / 20^{\circ} / 16^{\circ}$ \\
\hline Injection pressure (bar) & 450 \\
\hline Fuel injected (mg/cycle) & 41.5 \\
\hline
\end{tabular}

Table 2 Fuel Properties of for the experiments

\begin{tabular}{|c|c|c|c|c|}
\hline Properties & Diesel & & & \\
\hline $\begin{array}{c}\text { Kinematic viscosity (40deg.C), } \\
\mathrm{mm}^{2} / \mathrm{s}\end{array}$ & 2.601 & & & \\
\hline Flash point (deg.C) & 94.5 & & & \\
\hline Density (15deg.C), (kg/l) & 0.8307 & & & \\
\hline Cetane number (-) & 43 & & & \\
\hline Low calorific value $(\mathrm{MJ} / \mathrm{kg}$ & 45.83 & & & \\
\hline $\mathrm{O} / \mathrm{H} / \mathrm{C}(\mathrm{wt} . \%)$ & 0 / $13.7 / 86$ & & & \\
\hline Total sulfur (wt.\%) & 0.030 & & & \\
\hline Distillation point(deg.C) $90 \%$ & \multicolumn{4}{|c|}{ Table 3.5 Engine operating conditions } \\
\hline & Engine speed (rpm) & $\begin{array}{c}1600 \\
\text { (Baseline) }\end{array}$ & 1600 & 1600 \\
\hline & $\begin{array}{l}\text { Start of Injection } \\
\left({ }^{\circ} \mathrm{CA} \text { BTDC }\right)\end{array}$ & 25 & 20 & 12 \\
\hline & Injector pressure (MPa) & & 45 & \\
\hline & Injection duration $\left({ }^{\circ} \mathrm{CA}\right)$ & $20^{\circ}$ & $20^{\circ}$ & $18^{\circ}$ \\
\hline & Load rate & $75 \%$ & $75 \%$ & $75 \%$ \\
\hline
\end{tabular}


Figures: 


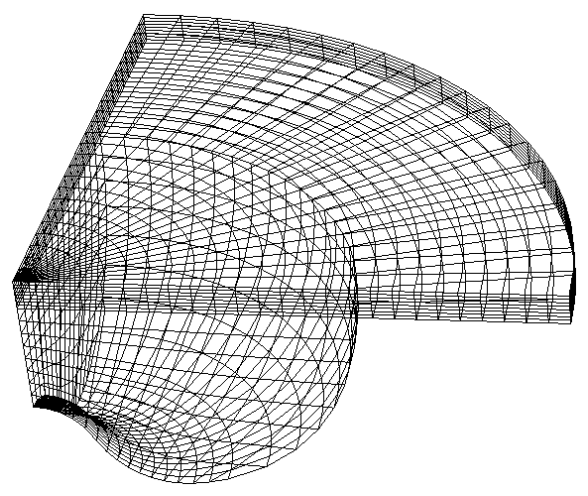

Fig.1 The computational mesh at TDC
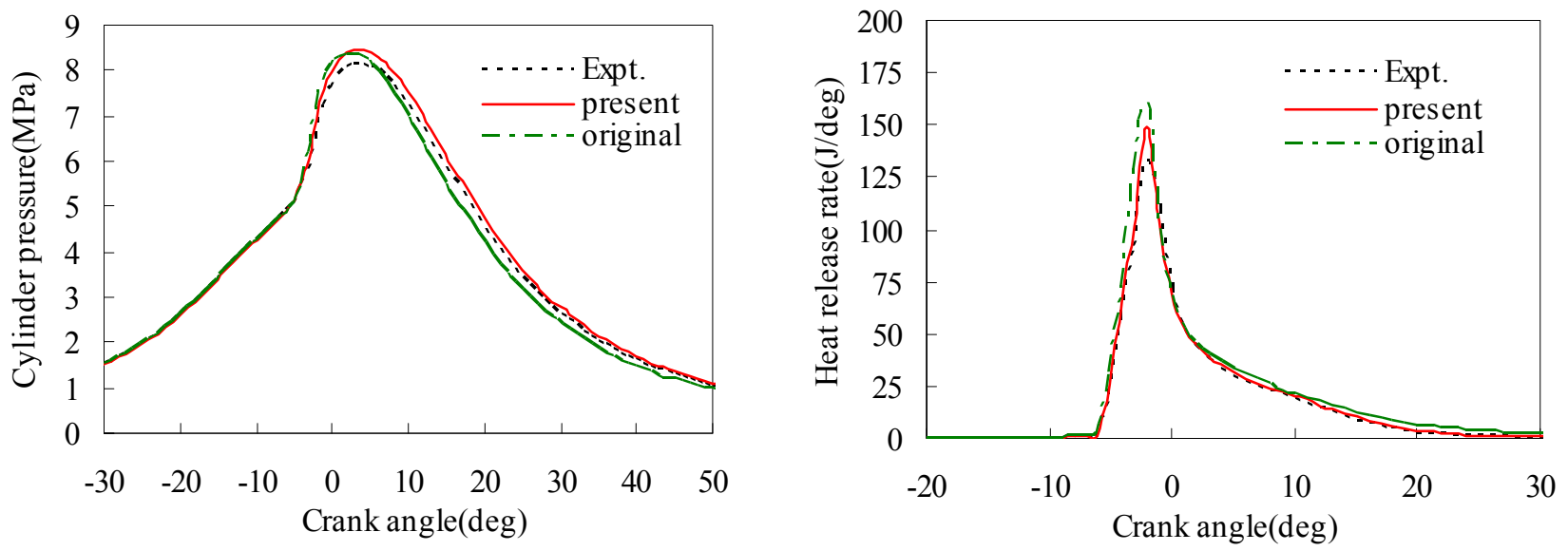

Fig.2 Comparison of measured and simulated cylinder pressures and heat release rate for baseline engine case.

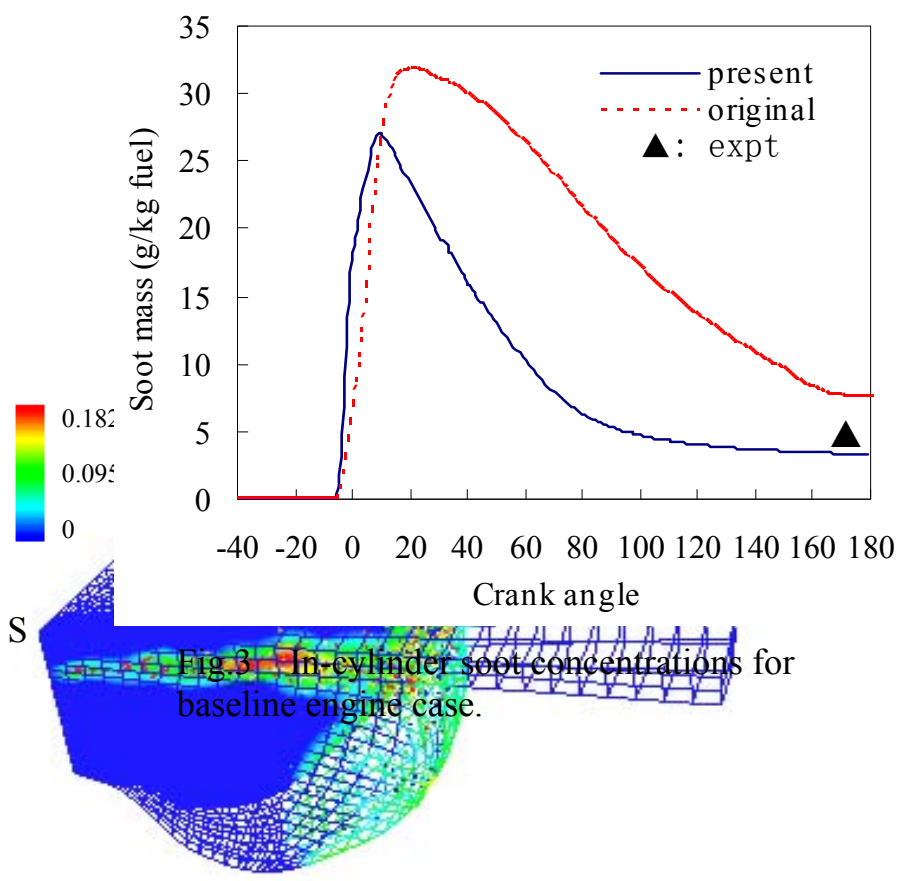

Fig.4 Fuel vapor mass fraction field and droplet distribution at $10^{\circ} \mathrm{BTDC}$ for baseline engine case. 


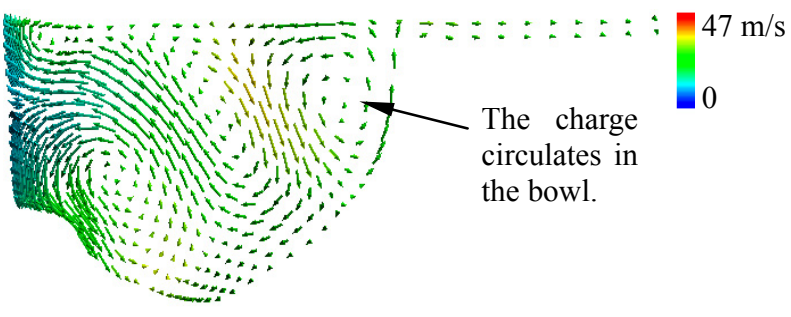

Fig.5 A typical velocity vector at $4{ }^{\circ} \mathrm{CA}$ ATDC for baseline engine case. 

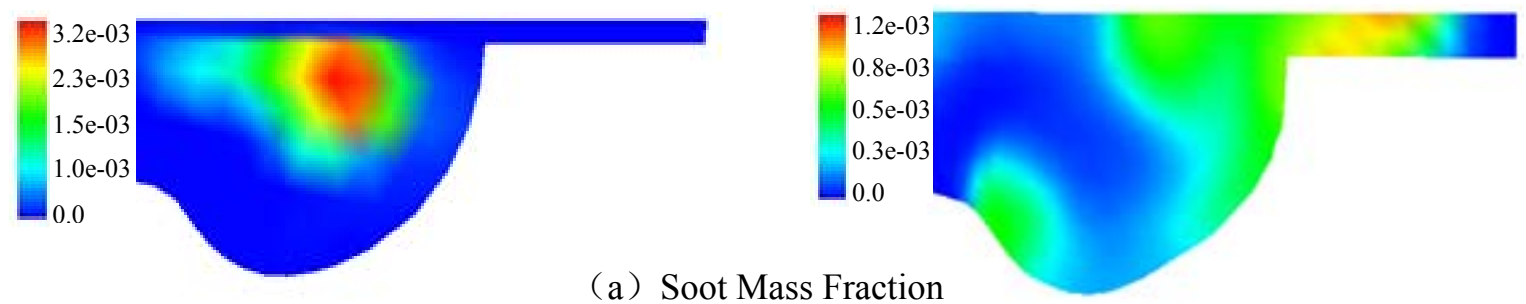

(a) Soot Mass Fraction
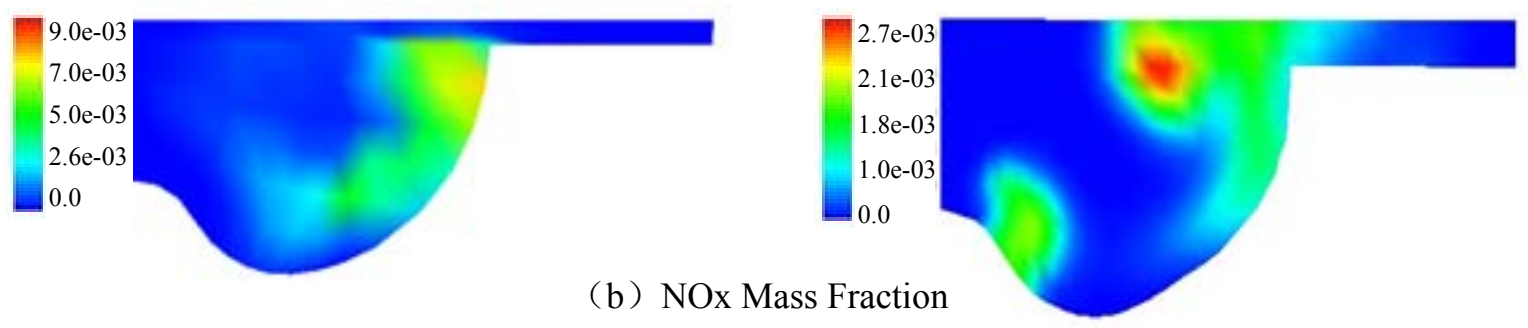

(b) NOx Mass Fraction

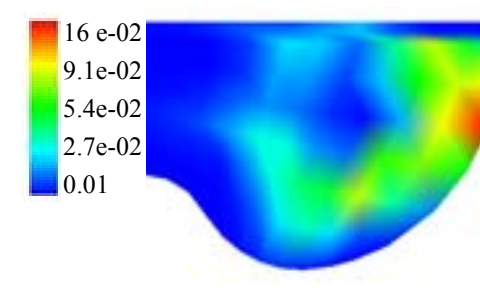

$5^{\circ} \mathrm{ATDC}$

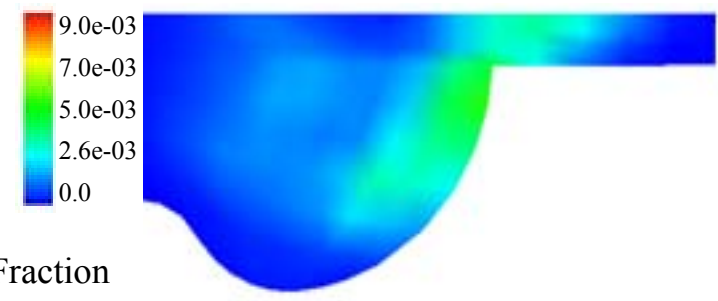

$20^{\circ}$ ATDC

26

Fig. 7 Spatial mass distributions of soot, $\mathrm{NOx}$ and $\mathrm{OH}$ in a combustion chamber in baseline engine condition. 


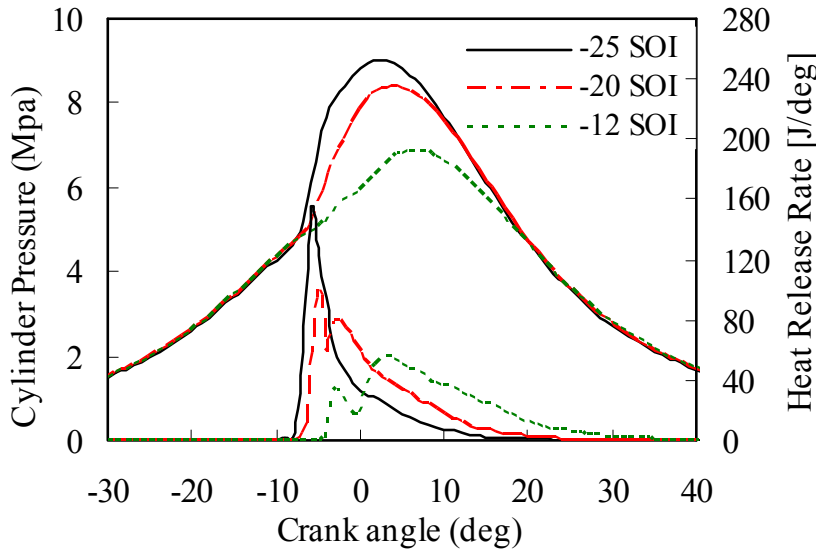

Fig.9 Cylinder pressure and Heat release rates at different fuel injection timing.

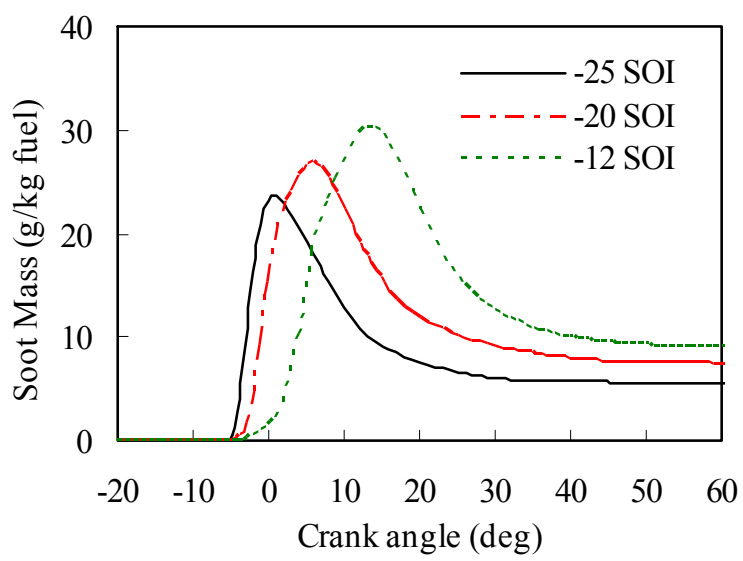

Fig.11 In-cylinder net soot concentrations at different fuel injection timings. ${ }_{28}$

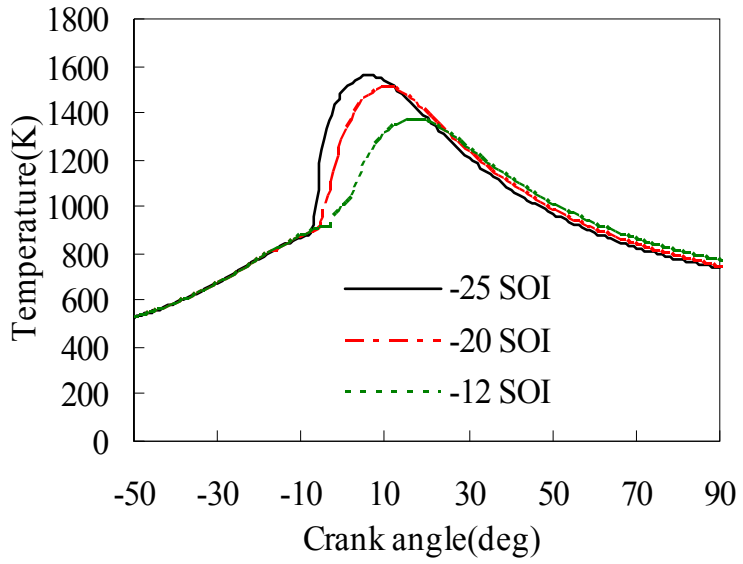

Fig.10 Average in-cylinder temperature at different fuel injection timings.

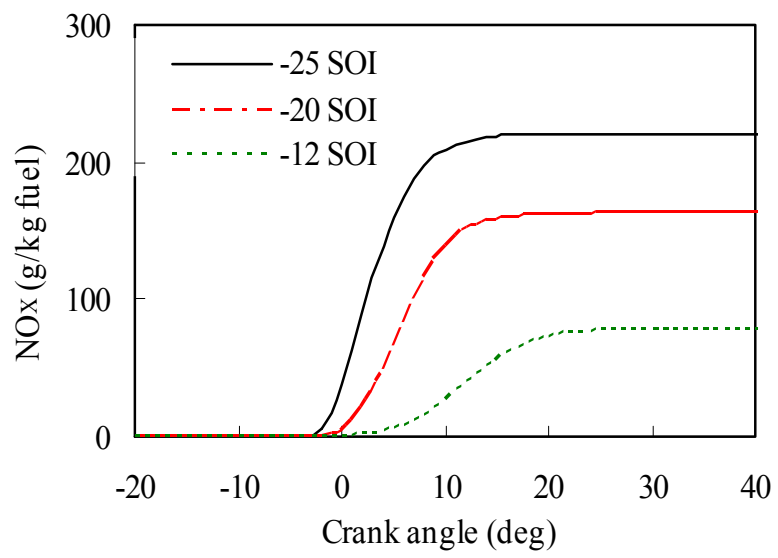

Fig.12 In-cylinder NO concentrations at different fuel injection timings. 
